\title{
MicroRNA Analysis of ATM-Deficient Cells Indicate PTEN and CCDN1 as Potential Biomarkers of Radiation Response
}

\author{
Jane Bryant \\ Technological University Dublin \\ Lisa White \\ Technological University Dublin \\ Natasha Coen \\ Our Lady's Children's Hospital, Crumlin, Dublin
}

See next page for additional authors

Follow this and additional works at: https://arrow.tudublin.ie/radart

Part of the Medicine and Health Sciences Commons

\section{Recommended Citation}

Bryant J, White L, Coen N, Shields L, McClean B, Meade AD, Lyng FM, Howe O. MicroRNA Analysis of ATMDeficient Cells Indicate PTEN and CCDN1 as Potential Biomarkers of Radiation Response. Radiat Res. 2020 Jun 1;193(6):520-530. doi: 10.1667/RR15462.1. PMID: 32216710.

This Article is brought to you for free and open access by the Radiation and Environmental Science Centre at ARROW@TU Dublin. It has been accepted for inclusion in Articles by an authorized administrator of ARROW@TU Dublin. For more information, please contact arrow.admin@tudublin.ie, aisling.coyne@tudublin.ie, gerard.connolly@tudublin.ie.

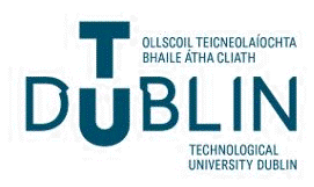




\section{Authors}

Jane Bryant, Lisa White, Natasha Coen, Laura Shields, Brendan McClean, Aidan Meade, Fiona Lyng, and Orla L. Howe

This article is available at ARROW@TU Dublin: https://arrow.tudublin.ie/radart/81 


\section{1 microRNA analysis of ATM-deficient cells indicate PTEN and}

\section{CCDN1 as potential biomarkers of radiation response}

3

4 Jane Bryant ${ }^{1}$, Lisa White ${ }^{1,2}$, Natasha Coen ${ }^{3}$, Laura Shields ${ }^{4}$, Brendan McClean ${ }^{4}$, Aidan D.

5 Meade $^{1,5}$, Fiona M. Lyng ${ }^{1,5}$, Orla Howe H,2 $^{1,2}$

$6{ }^{1}$ Radiation and Environmental Science Centre (RESC), FOCAS Research Institute, Technological

7 University Dublin (TU Dublin), City Campus, Dublin 8, Ireland.

$8{ }^{2}$ School of Biological and Health Sciences, TU Dublin, City Campus, Dublin 8, Ireland.

$9{ }^{3}$ Department of Clinical Genetics, Division of Cytogenetics, Our Lady's Children's Hospital,

10 Crumlin, Dublin 12, Ireland.

${ }^{4}$ Medical Physics Dept., St Luke's Radiation Oncology Centre, Rathgar, Dublin 6, Ireland

${ }^{5}$ School of Physics \& Clinical \& Optometric Sciences, TU Dublin, City Campus, Dublin 8, Ireland.

Corresponding author:

Prof. Orla Howe

Rm G-029, School of Biological \& Health Sciences,

Technological University Dublin,

City Campus,

Kevin St, Dublin 8,

Ireland.

Email: orla.howe@dit.ie 
Bryant J, White L, Coen N, Shields L, McClean B, Meade A.D, Lyng F.M, Howe O. microRNA analysis of ATM-deficient cells indicate PTEN and CCDN1 as potential biomarkers of radiation response. Radiat.Res

ABSTRACT

Genetic and epigenetic profile changes associated with individual radiation sensitivity are well documented and have led to an increase in our understanding of the mechanisms of the radiation-induced DNA damage response. However, the quest to identify reliable biomarkers of individual radiation sensitivity is on-going. Herein, we report a multi-biomarker approach using traditional cytogenetic biomarkers, DNA damage biomarkers and transcriptional microRNA (miR) biomarkers coupled with their potential gene targets to identify radiosensitivity in ATM (Ataxia-Telangectasia Mutated)-deficient lymphoblastoid cell lines (LCL) and ATM proficient cell lines that were used as controls.

Cells were irradiated with 0.05 Gy and 0.5 Gy using an Elekta Precise linac, with shamirradiated cells as controls. At 1 hour post irradiation, cells were fixed for $\mathrm{pH} 2 \mathrm{AX}$ analysis as a measurement of DNA damage, and cytogenetic analysis using the G2 chromosomal sensitivity assay, G-Banding and FISH techniques. RNA was also isolated for genetic profiling by microRNA (miR) and RT-PCR analysis. A panel of $752 \mathrm{miR}$ were analysed, and potential target genes phosphatase and tensin homolog (PTEN) and cyclin D1 (CCND1) measured.

The cytogenetic assays revealed that although the control cell line had functional cell cycle checkpoints, the radiosensitivity of the control and AT cell lines were similar. Analysis of DNA damage in all cell lines, including an additional control cell line, showed elevated $\mathrm{\gamma H} 2 \mathrm{AX}$ levels 
for only one A-T cell line. Of the $752 \mathrm{miR}$ panel analysed, $8 \mathrm{miR}$ were found to be up-regulated, with 6 miR down-regulated in the AT cells compared to the control. Up-regulated miR-152$3 p$, miR-24-5p and miR-92-15p and all down-regulated miR were indicated as modulators of PTEN and CCDN1. Further measurement of both genes validated their potential role as radiation response biomarkers. The multi-biomarker approach not only revealed potential candidates for radiation response but also additional mechanistic insights of response in AT deficient cells.

\section{INTRODUCTION}

In the last decade, the definition and classification of ionizing radiation biomarkers have been reported through several European Union Framework 7 multidisciplinary consortia such as Multibiodose (2010-2013), RENEB (Realizing the European Network in Biodosimetry (20122015)) and DoReMi (Low dose Research towards multidisciplinary Integration (2010-2015)) with the multipurpose use of biomarkers for epidemiological and biodosimetry investigations (1-4). These include biomarkers of low dose exposure and biological response, individual susceptibility and early detection of a radiation-induced health effect, of which considerations to the characteristics of a good biomarker and the useful in vitro approaches have been made. Although the DoReMi project was completed in 2015, research has continued under Melodi (Multidisciplinary European Low Dose Initiative (5)) and the DoReMi multidisciplinary report (4) was later updated to include novel radiation biomarkers emerging from technical advances in metabolomics and transcriptomics, and to critique the current status of biomarkers (6). A roadmap for the development of biomarkers from discovery to implementation was presented for biomarkers of low dose exposure and early or late 
radiation effects. The authors highlighted that the majority of potential biomarkers are in the development stage with only one biomarker that has progressed to the final stages of development with IR specific mRNA transcript profiles for FDXR. This gene has been reported in many proposed gene signature panels due to dose-dependent induction in different cell and tissue types (7-10). Furthermore, inter-comparison laboratory or biodosimetry studies have demonstrated that both single genes and gene panels can be used to estimate exposure of samples with the same accuracy and sensitivity of established and traditional cytogenetic assays (11-12).

The DNA damage response (DDR) pathways are potential targets for transcriptional biomarkers of cancer susceptibility and radiation exposure; in particular the ATM/chk2/p53 pathway, which responds to radiation-induced double strand breaks (DSB) leading to cell cycle arrest or DNA repair. The DSB are sensed by the MRN complex (MRE11- Rad50-NBS-1) leading to ATM activation, phosphorylation of serine 139 of $\mathrm{\gamma H} 2 \mathrm{AX}$ and extension around the DSB, initiating repair protein assembly (13-14). Consequently, $\mathrm{pH} 2 \mathrm{AX}$ has been used as a biomarker of DNA damage and repair and for predicting radiosensitivity in individuals (15-17) and applied to a wide range of established cell lines, primary cell cultures and peripheral blood lymphocytes as well as 2-dimensional tissue models and tissue sections as reviewed by Rothkamm et al (18). The role of ATM, a PI3K-like kinase that is phosphorylated at specific serine/threonine sites when activated, is central to this pathway. Deficiencies in the ATM gene lead to phenotypic elevated radiosensitivity observed in clinical conditions such as Ataxia Telangiectasia (AT) and AT-like disorders (ATLD) (19-21). After DSB are sensed, the cell cycle must be halted to allow sufficient time for DNA repair processes, facilitated through ATM- activated Chk2. This leads to p53- mediated inhibition of cyclins and cyclin-dependent kinases, such as Cyclin D1 (CCDN1) and CDK4/6 at the G1 cell cycle checkpoint (22). Failure to 
undergo DNA repair may result in permanent cell cycle arrest, enhanced apoptosis or cellular senescence. The PI3K/Akt pathway is also involved in the survival of cells after IR-induced DNA damage, through overriding the G2/M cell cycle arrest mechanism; conversely inhibition of PI3K or Akt, for example through the tumour suppressor PTEN, induces cell apoptosis and therefore elevates cellular radiosensitivity (23-25).

Further transcriptomic analyses have shown that microRNA (miR) are promising biomarkers of radiation oncology (26). They are small, non-coding RNA molecules of 19-22 nucleotides that regulate more than $50 \%$ of cell protein coding genes and regulate important processes of the DNA damage response such as DNA repair, cell cycle control and apoptosis. It has previously been shown that important genes of these processes (such as CDKN1, SESN1, ATF3, MDM2, PUMA and GADD45A) were upregulated in stimulated T cells in response to IR with a significant dose- and time-dependent modification of miR expression (specifically miR-34-5p and miR-182-5p) (27-28).

Given the current published evidence associating the ATM/Chk2/P53 pathway with elevated radiosensitivity and potentially regulated by $\mathrm{miR}$, normal and AT radiosensitive lymphoblastoid cell lines were used to measure IR-induced DNA damage using the classic cytogenetic and DNA damage biomarkers followed by miR screening and identification of gene targets in a multi-biomarker approach. All biomarkers selected for this study were based on the DoReMi (Low dose Research towards multidisciplinary Integration) multidisciplinary biomarker reports by Pernot et al (4), and Hall et al (6), and the recent report which reviews the progress made in low dose health risk research by the DoReMi consortium (29). 
116 Epstein-Barr immortalised lymphoblastoid cell lines (LCLs) coded; C1, 2139, AT2Bi and AT3Bi were used for this study. C1 and 2139 cell lines were derived from healthy donors and kindly gifted by the Queensland Institute of Medical Research, Australia and the Institut Curie, Paris, respectively. The AT2Bi and AT3Bi cell lines were derived from clinically established AtaxiaTelangectasia patients and kindly gifted from the College of Medical and Dental Sciences, University of Birmingham, UK. Both AT2Bi and AT3Bi are known to have defective Ataxia Telangiectasia- mutated (ATM) protein causing the typical clinical and cellular manifestations of AT including heightened radiosensitivity (30). C1, 2139, AT2Bi and AT3Bi lymphoblast cells were cultured in RPMI 1640 medium (Sigma Aldrich, Wexford, Ireland) supplemented with 12.5\% FBS and $1 \%$ L-Glutamine (Sigma Aldrich), at $37^{\circ} \mathrm{C}$ and $5 \% \mathrm{CO}_{2}$. All cell lines were seeded at a density of $2 \times 10^{5} / \mathrm{ml}$ and passaged once a density of $1 \times 10^{6} / \mathrm{ml}$ cells had been reached. Cells were seeded 18 hours prior to irradiation, a T25 flasks at a density of $1 \times 10^{6}$ cells $/ \mathrm{ml}$ (G2 chromosomal radiosensitivity assay), $2 \times 10^{4}$ cells in total (growth curves), or $2 \times 10^{5} / \mathrm{ml}(\gamma \mathrm{H} 2 \mathrm{AX}$ and molecular experiments) at a final volume of $5 \mathrm{ml}$ per T25 flask (Sarstedt, Numbrecht, Germany).

\section{Irradiation Conditions}

Cells were irradiated using a $6 \mathrm{MV}$ photon beam produced by an Elekta Precise linear accelerator (LINAC) at St. Luke's Hospital, Dublin, operating at a nominal dose rate of $6 \mathrm{~Gy} / \mathrm{min}$. The LINAC was calibrated in accordance with the 1990 IPSM code of practice by the Medical Physics Department at St. Luke's Hospital (31), with 100 Monitor Units (MU, a measure of 'beam on' time) delivered a dose of $1 \mathrm{~Gy}$ at $1.4 \mathrm{~cm}$ deep in water positioned 100 $\mathrm{cm}$ from the source for a $10 \times 10 \mathrm{~cm}^{2}$ field. To achieve a uniform irradiation of flasks, the 
irradiation conditions were altered from those at calibration. A $30 \times 35 \mathrm{~cm}^{2}$ field was used to deliver each dose. The flasks were also positioned $10 \mathrm{~cm}$ deep in a water equivalent phantom $90 \mathrm{~cm}$ from the source in which $100 \mathrm{MU}$ delivers a dose of $0.812 \mathrm{~Gy}$ at $10 \mathrm{~cm}$ deep in water for a $10 \times 10 \mathrm{~cm}^{2}$ field. The number of $\mathrm{MU}$ required to deliver each of the doses outlined were corrected for the different scatter conditions present with the larger field size $\left(30 \times 35 \mathrm{~cm}^{2}\right)$. Therefore, a correction factor of 1.1372 was applied, which is the ratio of the field area of a large field to a smaller one. Thus, at $90 \mathrm{~cm}$ from the source, $100 \mathrm{MU}$ delivers a dose of 0.9234 Gy $(0.812 \times 1.1372)$, and therefore the delivery of 0.05 Gy required $6 \mathrm{MU}$ and $0.5 \mathrm{~Gy}$ required delivered on the LINAC). The calculated doses were verified using Gafchromic EBT3 film was analyzed using FilmQA Pro (Ashland Inc., Bridgewater, NJ, USA).

\section{Cell Growth Assay}

To determine the effect of radiation on the growth potential of the cells, flasks were seeded cell numbers were calculated and analysed with reference to sham-irradiated controls. and irradiated as described above. At 5-7 days post- irradiation, cells were isolated and counted in duplicate using a Coulter cell counter (Beckman Coulter, Co Clare, Ireland). Total 
DNA damage was determined by $\mathrm{Y}-\mathrm{H} 2 \mathrm{AX}$ analysis and measured by flow cytometry. Cells were fixed at 1-hour post irradiation in $2 \%$ paraformaldehyde and stored in $70 \%$ ethanol at $-20{ }^{\circ} \mathrm{C}$. To stain, cells were permeabilised using $0.25 \%$ Triton $\mathrm{X}$, followed by blocking with a

$4 \%$ FBS solution in PBS for 30 minutes. A primary antibody solution (anti-phospho-histone H2A.X (Ser139), clone JBW301, 1:500; Merck Millipore, Darmstadt, Germany) was added and incubated overnight at $4{ }^{\circ} \mathrm{C}$, followed by a 1-hour incubation with the secondary antibody (F(ab')- Goat anti-Mouse IgG (H+L), Alexa Fluor-488, 1:200; Thermo Fisher, Carlsbad, CA, USA) at room temperature. Cells were washed, counterstained with $1 \%$ propidium iodide solution and analysed on an Accuri C6 flow cytometer (BD, Oxford, UK). The mean fluorescence of 10,000 cells was calculated using the Accuri C6 Sampler software, with cells stained only with the secondary antibody acting as a negative control for each sample.

\section{G2 chromosomal radiosensitivity assay}

The G2 Chromosomal radiosensitivity assay as previously reported for whole blood lymphocytes (35-37), was applied to all 2139, AT2Bi and AT3Bi cells to measure radiationinduced cell cycle checkpoint response by mitotic indices and G2 chromosomal radiosensitivity. The mitotic index (MI) was calculated by counting the ratio of cells in metaphase to all cells on the slide up to 1000 cells in total for each dose ( 0 Gy and $0.5 \mathrm{~Gy}$ ) and cell line. Radiation-induced mitotic inhibition (RIMI) was calculated by subtracting the $0.5 \mathrm{~Gy}$ MI from the 0 Gy MI. A G2 radiosensitivity score was assigned to each of the cell lines and irradiation dose by calculating the total number of chromosomal aberrations per 100 metaphases scored for each cell line and dose. A radiation-induced G2 score (RIG2) was 
calculated by subtracting the spontaneous aberrations in the $\mathrm{G} 2$ score at $0 \mathrm{~Gy}$ from those recorded at $0.5 \mathrm{~Gy}$.

\section{Cytogenetic G-Banding and karyotyping}

Cytogenetic preparations were made from irradiated 2139 and AT (AT2Bi and AT3Bi) LCL according to the G2 chromosomal radiosensitivity assay. For G-Banding, the metaphase spreads on glass slides were covered with $30 \%$ hydrogen peroxide solution for one minute followed by a wash with $0.9 \% \mathrm{NaCl}$ solution. The metaphase preparations were then placed in trypsin solution for 2 mins, washed with Gurr buffer $(\mathrm{pH} 8)$ and then stained in $1 \mathrm{ml}$ of Leishmann: Gurr buffer (1:2) solution for $1 \mathrm{~min}$. The slides were washed with Gurr buffer, then distilled water and dried before they were mounted with a coverslip using DPX. Each slide was evaluated under the microscope set up for bright-field use, noting conditions of microscope and analysed for chromosomal aberrations

Fluorescent In Situ Hybridisation (FISH)

Cytogenetic preparations (metaphase spreads as above) obtained from radiation- exposed 2139, AT2Bi and AT3Bi LCL were soaked in sodium chloride and sodium citrate buffer (SCC) for 2 mins at $37^{\circ} \mathrm{C}$, before being applied to/ treated with protease solution for $30-40$ seconds at $37^{\circ} \mathrm{C}$. Slides were then washed in $1 \times$ PBS, dehydrated in an ethanol series $(70 \%, 85 \%$ and 100\%) for 2 minutes each at RT and air dried before hybridisation. Hybridisation FISH probes were used to identify deletions or rearrangements in ATM-TP53 particularly for the AT cells (AT2Bi and AT3Bi). Probes for ATM-TP53 were used to confirm the presence of ATM or TP53 gene in all LCL. Conditions such as B-cell chronic lymphocytic leukaemia (B-CLL), a malignancy often associated with Ataxia-Telangectasia has shown deletions in the genes of $\operatorname{ATM}(38,39)$ 
and P53 (40). Probes were mixed according to the manufacturer's instructions and the required amount was added to each slide. Slides were transferred to a Hybrite machine with the selected Hybridisation program of $75^{\circ} \mathrm{C}$ for 2 min and $37^{\circ} \mathrm{C}$ for 20 hours. When hybridised samples were removed, the slides were immersed in wash solution $(0.4 \times S S C / 0.3 \%$ NP 40$)$ for 2 minutes and then transferred into a solution of $2 \times S S C / 0.1 \%$ NP40 for a minimum of 1 minute. DAPI $(20 \mu \mathrm{l})$ was added as a counterstain and slides were mounted in coverslips. For FISH microscopy, 100 Interphase cells were recorded.

\section{MicroRNA expression}

An expression panel of 752 miR was performed on 2139, AT2Bi and AT3Bi cell lines (Exiqon,

Vedbaek, Denmark), in accordance with company protocols. Briefly, RNA (50ng) was reverse transcribed and cDNA assayed in $10 \mu \mathrm{I}$ PCR reactions (miRCURY LNA ${ }^{\mathrm{TM}}$ universal RT microRNA PCR, Polyadenylation and CDNA synthesis kit, ExiLENT SYBR ${ }^{\circledR}$ Green master mix). The amplification was performed in a LightCycler ${ }^{\circledR} 480$ Real Time PCR System (Roche) in 384 well plates. Melting curve and $\mathrm{Cq}$ values were analysed using Roche LC software. Cq values were calculated as the second derivative, with values greater than 37 omitted from further analysis. All data was normalized to the average of assays detected in all samples (average - assay Cq).

\section{Gene Expression}

Irradiated LCL were analysed for selected PTEN and CCDN1 gene expression by Real Time PCR

224 (RT-PCR). RNA was extracted from cells using the phenol-chloroform method and concentration measured using the Nanodrop (Maestrogen, Las Vegas, NV, USA). CDNA was synthesised using the q-script cDNA kit (Quanta Bio, Beverly, MA, USA), according to manufacturer's instructions. Primers for Tubulin, PTEN and CCND1 were designed (Table 1) and synthesised (Sigma Aldrich), and reactions were performed in duplicate in 96 well plates 
(Applied Biosystems, Carlsbad, CA, USA). Each reaction was composed of $10 \mu$ I SYBR Green with low ROX, (Kapa Biosystems, London, UK), $1 \mu$ l of forward and reverse primers, $6 \mu$ I PCR grade water, and $2 \mu \mathrm{l}$ cDNA. Non template controls replaced cDNA with $2 \mu \mathrm{I}$ PCR grade water. Reactions were run for 45 cycles on AB 7500 fast PCR cycler (Applied Biosystems).

Table 1 Forward and reverse primer sequences for housekeeping gene Tubulin, and for targets PTEN and CCND1

\begin{tabular}{lll}
\hline Gene & Forward Sequence & Reverse Sequence \\
\hline Tubulin & 5'GCTTCTTGGTTTTCCACAGC'3 & 3'CTCCAGCTTGGACTTCTTGC'5 \\
PTEN & AGACAAATTCGGGCTATTCTGC & ACCAGGTGCTTCATAGAGTAGG \\
CCND1 & GACAGGTCACATCAGAAAGAGC & CCTTCAGAGTAATTTGCCCAGG \\
\hline
\end{tabular}

\section{Statistical Analysis}

All statistical analysis was performed using Microsoft Excel, versions 2010-2016. Mean and standard deviations were calculated, and significance was determined using paired or unpaired t-tests of each radiation dose relative to its $0 \mathrm{~Gy}$ control, for each individual cell line, as appropriate.

\section{RESULTS}

Cell Growth assay for monitoring cellular viability

All cell lines were irradiated to 0.05 and $0.5 \mathrm{~Gy}$ and cultured for 5 days to measure growth potential. Percentage growth was calculated relative to the sham-irradiated control after 5 
days in culture, and counted using a Coulter Counter and displayed in Figure 1(A). After 5 days in culture the control 2139 cells indicated a linear dose response for each low dose $(0.05$ and 0.5Gy) compared to the 0Gy control (Figure 1A). Similarly the AT cells (AT2Bi and AT3Bi) indicated a dose response for $0.5 \mathrm{~Gy}$ but not $0.05 \mathrm{~Gy}$. This was expected because we previously reported differential molecular mechanisms of Apoptosis for 0.05Gy compared to 0.5Gy between $1 \mathrm{hr}$ and $24 \mathrm{hr}$ direct irradiation (41). The additional control cell line $\mathrm{C} 1$ did not show a radiation dose response comparative to the 2139 control cells.

YH2AX Biomarker of DNA damage response

257

All cell lines were irradiated to 0.05 and $0.5 \mathrm{~Gy}$ and fixed for Gamma- $\mathrm{H} 2 \mathrm{AX}(\gamma \mathrm{H} 2 \mathrm{AX}$ ) analysis through flow cytometry as shown in Figure 1 (B). \% positive cells were calculated, and normalised to the sham-irradiated control of each cell line. Since the cytogenetic biomarker of radiosensitivity (G2 chromosomal radiosensitivity) did not discriminate $\mathrm{G} 2$ radiosensitivity between the control 2139 and AT cells (AT2Bi and AT3Bi), the $\mathrm{\gamma H} 2 \mathrm{AX}$ assay was employed to measure double strand breaks (DSBs) induced by radiation in all cells. An additional control cell (C1) with functional ATM similar to 2139 was also analysed. Fluorescent foci are equal to the number of DSB induced by IR. Figure 1B presents $\gamma \mathrm{H} 2 \mathrm{AX}$ positive cells in the $4 \mathrm{LCLS}$ at 1 hour post-irradiation. A modest increase in $\mathrm{YH} 2 \mathrm{AX}$ positive cells was evident in the AT3Bi cell line to 1.5 fold of the $0 \mathrm{~Gy}$ control, however this was not significant ( $p>0.05)$. Irradiation of the 2139 and AT2Bi cell line decreased $\mathrm{pH} 2 \mathrm{AX}$ levels below that of the sham-irradiated cells, however this was not significant $(p>0.1)$. There was no dose dependence of response in any cell line tested (Figure 1B). This assay was also performed at later timepoints with no observable trends between the cell lines and doses (data not shown). 
A

Cell Growth

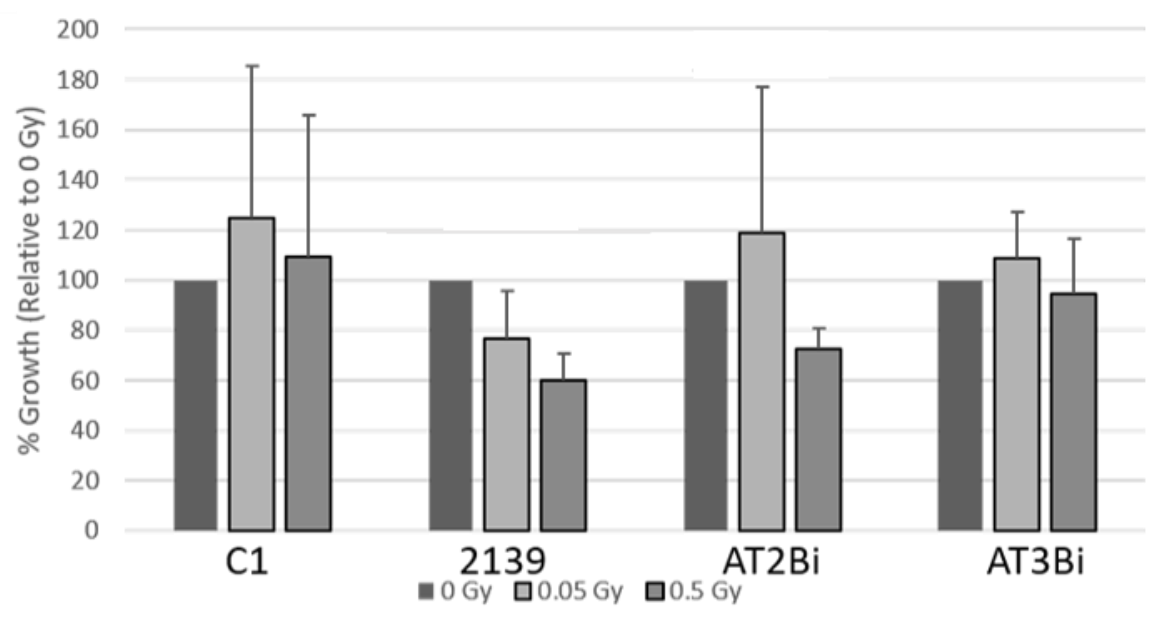

B

DNA Damage

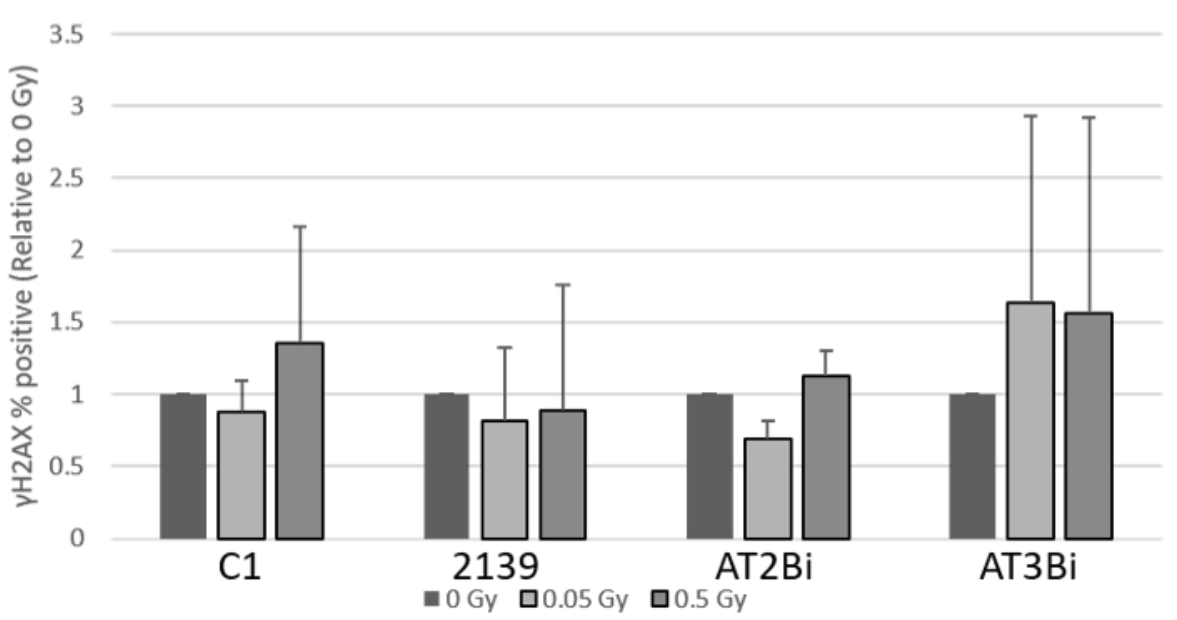

Figure 1: Control (C1 and 2139) and AT (AT2Bi and AT3Bi) LCLs exposed to 0Gy, 0.05Gy and +/- SD 
The G2 chromosomal radiosensitivity assay was used as cytogenetic biomarker of low-dose radiation-induced effects in the control 2139 and AT (AT2Bi and AT3Bi) lymphoblastoid cell lines. Assessment of mitotic indices (MI) through the G2 chromosomal radiosensitivity assay is a good indicator of cell cycle checkpoint response to ionising radiation, whereby radiationinduced mitotic inhibition (RIMI) is the calculated difference between the 0.5 Gy and 0 Gy MI. The normal expected $\mathrm{MI}$ for the $\mathrm{G} 2$ chromosomal radiosensitivity varies between 2-5\%, whereas the RIMI can be varied depending on cellular response to IR. All cell lines presented $\mathrm{MI}$ within the expected ranges for $0 \mathrm{~Gy}$ as presented in Figure $2 \mathrm{~A}$, however RIMI was more pronounced in 2139 (1.2) compared to AT2Bi (-0.3) and AT3Bi (0.6). This indicated that the control cells 2139 had superior cell cycle checkpoint efficacy compared to the AT cells, probably due to functional ATM. All cell lines presented elevated G2 chromosomal aberrations when irradiated to 0.5 Gy compared to their non-irradiated counterpart as presented in Figure 2B. Interestingly, the control 2139 cell line had similar radiation-induced G2 chromosomal radiosensitivity RIG2 (203 aberrations/100 metaphases) as the two AT cell lines AT2Bi and AT3Bi (134 and 183 aberrations/100 metaphases respectively), which indicated that although checkpoint response by $\mathrm{MI}$ appeared to be functional compared to the AT cells, radiation-induced chromosomal damage was similar to the AT cells. This finding merited further cytogenetic investigation, performed in collaboration with the Genetics the G-Banding Technique was performed on the 2139 and AT cells (AT2Bi and AT3Bi) and followed up with Fluorescent In-Situ Hybridisation (FISH) using an ATM/TP53 probe. The cytogenetic analysis on 2139 cells surprisingly showed a loss of a sex chromosome in all of the cells analysed (Figure 3), with no other single cell or recurrent aberrations detected. The loss of a sex chromosome is associated with the constitutional diagnosis of Turners syndrome in 

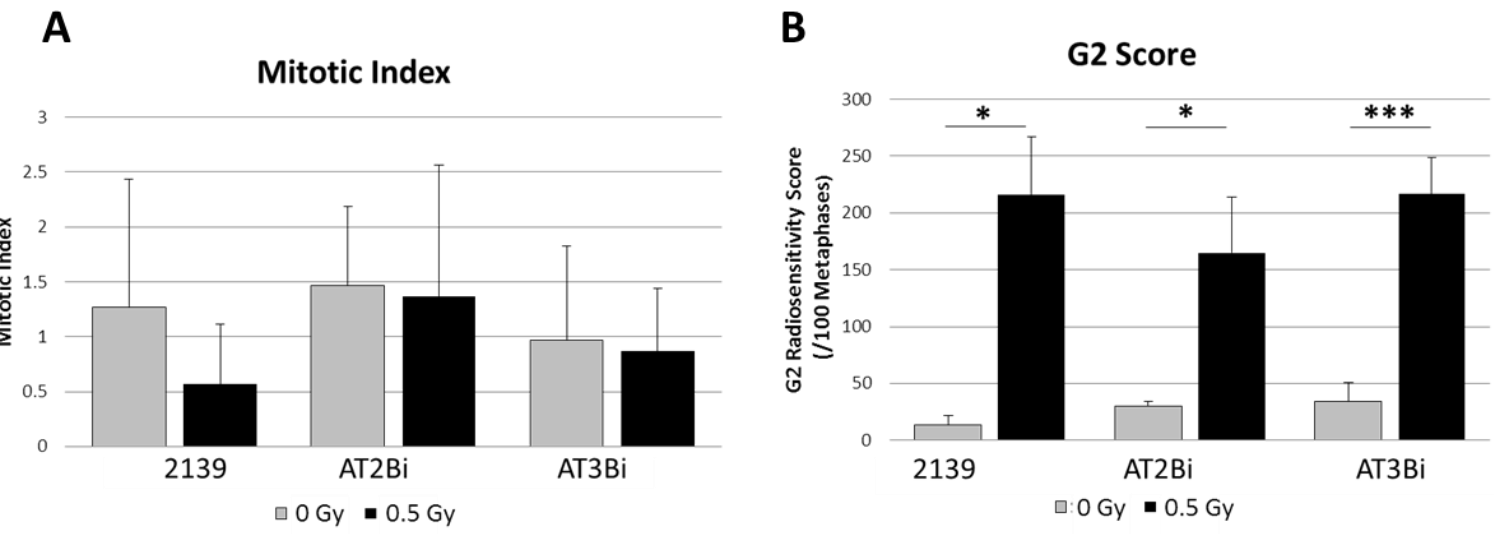

306

Figure 2: Control (2139) and AT (AT2Bi and AT3Bi) LCLs exposed to 0Gy (grey bars) and 0.5Gy

308 (black bars) in G2 chromosomal radiosensitivity assay for (A) Mitotic Index and (B) G2 score.

Data shown are representative of 3 independent experiments, mean $+/-S D,{ }^{*} p<0.01$, $* * * \mathrm{p}<0.005$. 


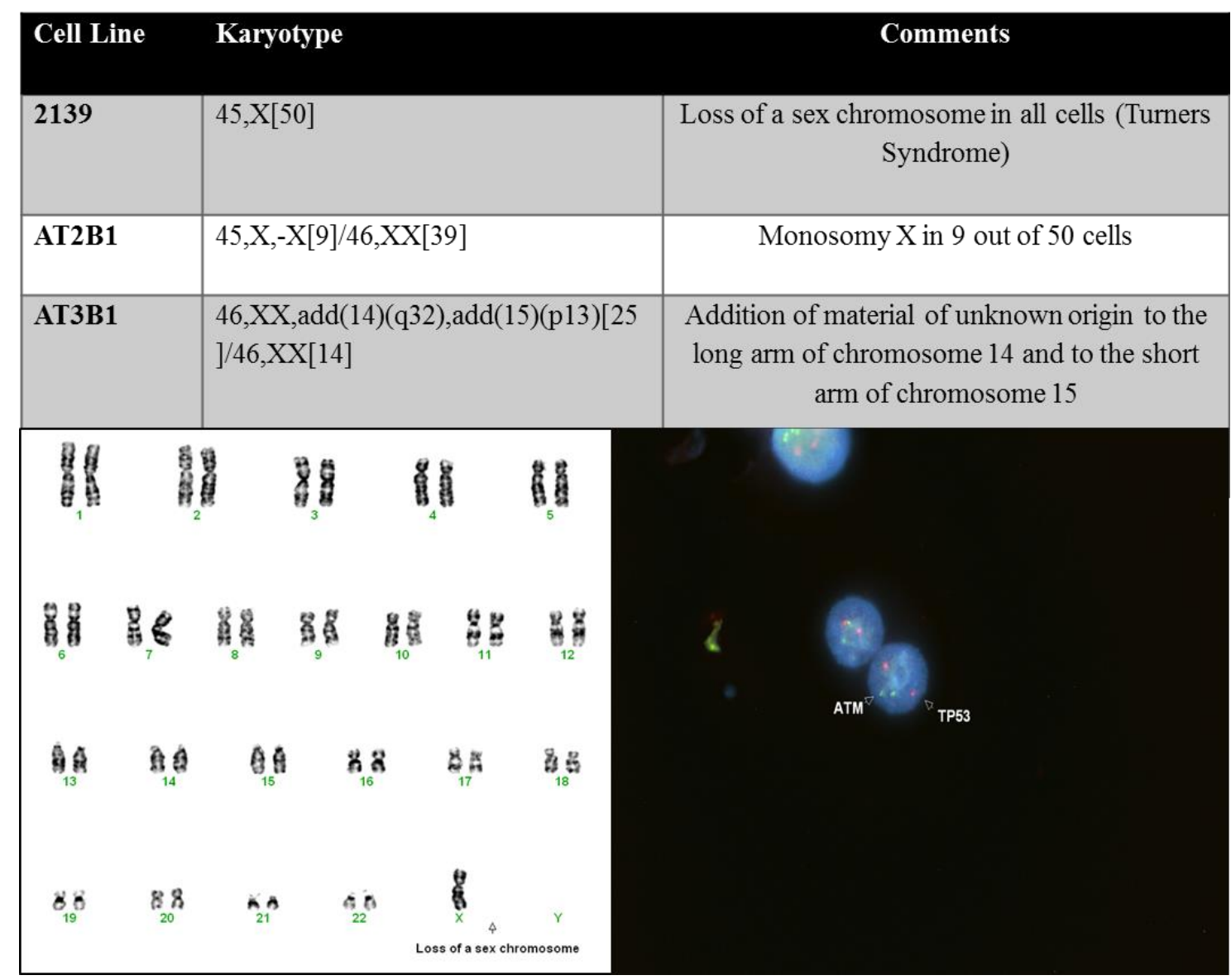

Figure 2: G-banding Karyotype report on 2139 and AT (AT2Bi and AT3Bi) LCLs reveal loss of sex chromosome $X$ in 2139 cells (bottom left) and two copies of ATM and TP53 in all cells

\section{MicroRNA biomarkers of radiation response}

MicroRNA (miR) analysis was performed on the control (2139) and two AT (AT2Bi, AT3Bi) cell lines, to generate miR expression profiles and elucidate the efficacy of miR as a biomarker of radiation response, compared to the cytogenetic and DNA damage biomarkers shown in Figures 1-3. Figure 4A illustrates a heatmap presenting the most highly expressed miR in the cell profiles, which were then further analysed to determine their increase or decrease in cells deficient in ATM relative to the mean of all cell lines (Figures 4B, 4C).

While all three cells lines showed differences in overall miR expression profiles, there were common patterns between the two AT cell lines, which differed from normally responding 
cells (Figure 1A). MiR424-5p presented the most marked differential expression between 2139 and both AT cell lines, with a 3.8-fold decrease in normally responding cells, and a 1.9fold increase in ATM-deficient cells (Figure 4B). MiR618 also decreased in normally responding cells by 2.5 -fold relative to the mean, while expression increased in both AT cell lines (Figure 4B). Conversely, miR335-3p increased in normally responding cells by 3.4- fold, with a decrease in both AT cells lines by an average of 1.7 fold relative to the mean (Figure $4 C)$.

\section{MicroRNA biomarkers of radiation response}

MicroRNA (miR) analysis was performed on the control (2139) and two AT (AT2Bi, AT3Bi) cell lines, to generate miR expression profiles and elucidate the efficacy of miR as a biomarker of radiation response, compared to the cytogenetic and DNA damage biomarkers shown in average of 1.7 fold relative to the mean (Figure 4C). cell profiles, which were then further analysed to determine their increase or decrease in cells deficient in ATM relative to the mean of all cell lines (Figures 4B, 4C).

While all three cells lines showed differences in overall miR expression profiles, there were common patterns between the two AT cell lines, which differed from normally responding eells ATM-expressing 2139 cells (Figure 4A). MiR424-5p presented the most marked differential expression between 2139 and both AT cell lines, with a 3.8-fold decrease in normally responding cells, and a 1.9- fold increase in ATM-deficient cells (Figure 4B). MiR618 also decreased in normally responding cells by 2.5 -fold relative to the mean, while expression increased in both AT cell lines (Figure 4B). Conversely, miR335-3p increased in normally responding cells ATM-expressing cells by 3.4- fold, with a decrease in both AT cells lines by an 


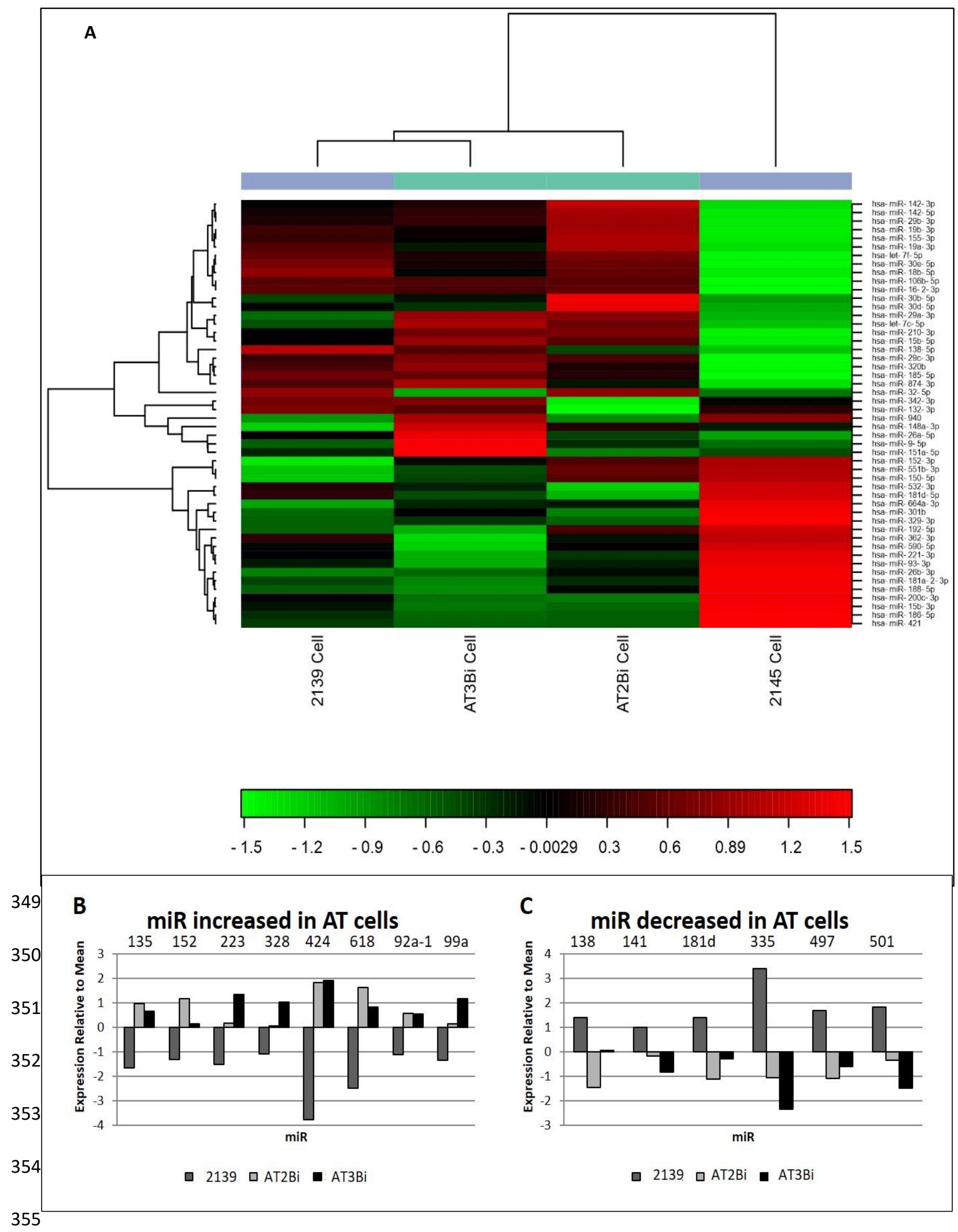


Figure 4: microRNA expression profiles for control (2139) and AT (AT2Bi, AT3Bi) cell lines as

377 analysed by Exiqon, Denmark. (A) An unsupervised heatmap analysis of the $\mathbf{5 0}$ most highly expressed miR in all three cell lines, ranging from green to red to reflect the level of decrease or increase from the mean. Increased (B) and decreased (C) miR expression in AT cells relative to the mean of all cell lines. Data shown are representative of one independent experiment.

Analysis of differentially expressed microRNA reveals common gene targets.

A panel of targets for the most differentially expressed miR was compiled through a systematic literature search, with emphasis on genes with roles in DNA damage response and repair. ATM is an integral part of this machinery and it was hypothesised that its deficiency in AT cell lines would be reflected in an increase or decrease in expression of a panel of miR. The mean expression of miR in all three cell lines (2139, AT2Bi and AT3Bi) was calculated and each individual cell line subtracted from the mean. MiR that were consistent in expression between both AT cell lines and different from the control cells were included, with the targets for those miR also detailed. As shown in Table 2, the predominant DNA repair-associated genes identified as targets of miR increased or decreased in AT cells included the tumour suppressor phosphatase and tensin homolog (PTEN) and the G1/S cell cycle checkpoint gene cyclin D1 (CCND1). These genes were both found to be directly and indirectly regulated by the miR of interest. 
Gene expression analysis of PTEN and CCND1 was carried out in normal (C1 and 2139) and AT

381

382

(AT2Bi and AT3Bi) cell lines. RT-PCR was performed on cDNA isolated from all cell lines to investigate the expression of miR target genes exposed to 0, 0.05 and 0.5 Gy IR. Fold increase of genes was calculated using the $2^{\text {-ddCt }}$ method, relative to $0 \mathrm{~Gy}$ controls and an expression was recorded over a value of 1 (Y-axis). In Figure 5, it is evident that the expression of PTEN (Figure 5A) and CCDN1 (Figure 5B) was elevated after irradiation to $0.05 \mathrm{~Gy}$ relative to $0 \mathrm{~Gy}$ in 2139 and AT cells. Normally responding C1 cells showed a modest increase in expression of both genes in response to irradiation, however the relative increase did not exceed 2.2 fold (CCND1, $0.5 \mathrm{~Gy}$ ). The highest increase in PTEN expression was observed in AT3Bi cells, with a 35-fold increase relative to sham-irradiated cells, although this was not significant (Figure 5A). The largest increase observed in CCND1 expression was seen in 2139 cells, with a 6.4-fold increase over sham-irradiated cells. The AT cell lines showed a more modest increase of 2.6 (AT2Bi) and 4.7-fold (AT3B) (Figure 5B). However, due to inter-experimental variation, these fold changes were not significant.

Table 2: Expression panel of miR upregulated or downregulated in both AT cell lines compared to control cells, relative to the mean of all cell lines.

\begin{tabular}{lcll}
\hline miR & Expression in AT & Target & References \\
& cells relative to & (Indirect Target) & \\
& control cells & & \\
& & & \\
\hline hsa-miR-135a-5p & $\uparrow$ & FOXO1 (CCND1) & [42] \\
\hline
\end{tabular}




\begin{tabular}{llll}
\hline hsa-miR-152-3p & $\uparrow$ & PTEN & [43] \\
hsa-miR-223-3p & $\uparrow$ & FOXO1 (CCND1) & {$[44]$} \\
hsa-miR-328-3p & $\uparrow$ & TCF7L2 (CCND1) & {$[45]$} \\
hsa-miR-424-5p & $\uparrow$ & PTEN & [46] \\
hsa-miR-618 & $\uparrow$ & PI3K/Akt pathway & [47] \\
hsa-miR-92a-1-5p & $\uparrow$ & PTEN & {$[48]$} \\
hsa-miR-99a-5p & $\uparrow$ & AGO-2 (PTEN) & {$[49]$} \\
hsa-miR-138-5p & $\vee$ & CCND1 (PTEN) & {$[50,51]$} \\
hsa-miR-141-3p & $\vee$ & PTEN (CCND1) & {$[52,53]$} \\
hsa-miR-181d-5p & $\vee$ & PTEN & {$[54]$} \\
\hline hsa-miR-335-3p & $\vee$ & PTEN & {$[55]$} \\
hsa-miR-497-5p & $\vee$ & CCND1 & {$[56]$} \\
\hline
\end{tabular}

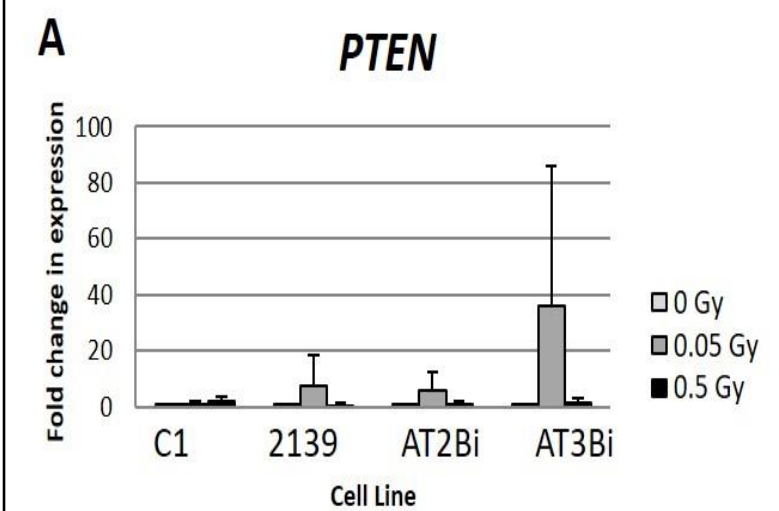

B

CCND1

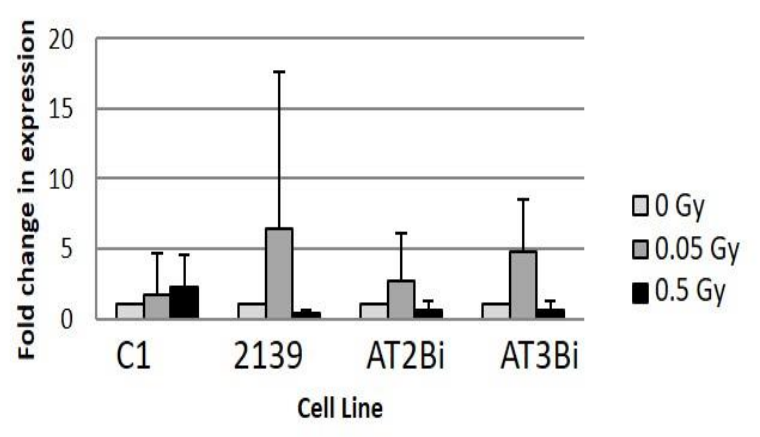

Figure 5: Expression of miR target genes PTEN and CCND1. (A) PTEN gene expression upregulated in both AT cells and 2139 compared to $\mathrm{C} 1 \mathrm{LCL}$ at $0.05 \mathrm{~Gy}$ compared to 0 and 0.5Gy IR. (B) CCDN1 gene expression also upregulated in AT cells and 2139 compared to C1 
at $\mathbf{0 . 0 5 G y}$. old increase of genes was calculated using the $2^{\text {-ddct }}$ method, relative to shamirradiated cells. Data shown are representative of 3 independent experiments, mean +/- SD. and through the multidisciplinary European Union DoReMi consortium (2010-2015), which arose from the original recommendations made by the High Level Expert Group (HLEG) on low dose radiation risk research (29). In particular, it was recognised that there was an urgent need for biomarkers of low dose radiation exposure, individual susceptibility and the effects of radiation damage (early and late) which have been since characterised by members of the consortium $(4,6)$. The authors of this manuscript were also involved in a part of DoReMi for investigating the use of Raman Spectroscopy as a novel tool and biomarker of individual radiation sensitivity. Raman Spectra can be generated from patient samples to produce a unique low dose IR-induced biochemical profile $(57,58)$. To validate and consolidate Raman Spectral analyses, the G2 Chromosomal radiosensitivity assay was used as a cytogenetic Biomarker of radiosensitivity because it was routinely carried out in our laboratory for different cohorts of patient lymphocytes and cell Ilines (35-37). In more recent years, our group has employed the use of $\mathrm{\gamma H} 2 \mathrm{AX}$ as a biomarker of DNA damage and individual radiosensitivity because it can yield quantitative results through flow cytometry with parallel qualitative confocal imaging and of which is more time-efficient than cytogenetics. Furthermore, previous reports show increased $\mathrm{yH} 2 \mathrm{AX}$ foci increased with increasing radiation dose in lymphoblastoid cell lines (59). Herein we applied both cytogenetic and $\mathrm{pH} 2 \mathrm{AX}$ biomarkers to assess the radiation sensitivity of normal ( $\mathrm{C} 1$ and 2139) and clinically characteristed AT (AT2Bi and AT3Bi) lymphoblastoid cell lines. Lymphoblastoid cell lines (LCLs) 
are T-lymphocytes immortalised with Epstein-barr virus and they were selected because parallel studies on whole blood lymphocytes from cohorts of patients were being carried out at the same time and therefore biomarker studies were limited. Although LCLs are not directly comparable to responses recorded in whole blood lymphocytes, they were advantageous for conducting the additional biomarker studies reported within. Similarly, the low doses selected for the experiments were based on the parallel blood studies that were carried out. It was surprising that the G2 chromosomal radiosensitivity scores in the AT cell lines were not significantly elevated compared to the control 2139 cells, although cell cycle checkpoint efficacy observed by mitotic indices (MI) and the calculated radiation-induced mitotic inhibition (RIMI) appeared to be superior in the 2139 cells compared to both AT cells. This would be expected if ATM is functional in the normal 2139 cells as ATM transduces the IRinduced DNA damage signal through a serine/threonine phosphorylation cascade. AT2Bi and AT3Bi cells were derived from clinically characterised AT patients and cellular features of radiosensitivity was previously established through the colony forming cell survival and chromosomal assays in which both AT cell lines showed similar spontaneous chromosomal aberration rates. However clinical and cellular heterogeneity was reported between the cell types (30). Given this reported heterogeneity between AT2Bi and AT3Bi, and the unexpected G2 chromosomal radiosensitivity response between the AT cells and 2139, a further cytogenetic analysis incorporating G-banding with karyotyping and Fluorescent In-Situ Hybridisation (FISH) using a dual ATM/TP53 probe set was performed. FISH was included in the analysis as TP53 is directly signalled by ATM phosphorylation and deletions of TP53 has been previously recored in $17 \%$ of B-cell leucocytic leukaemia (B-CLL) (40). Deletions in ATM in Ataxia-telangectasia patients have been long associated with malignancies such as leukameia and lymphomas $(38,39)$, and in particular older AT patients. Since both AT2Bi and 
AT3Bi were derived from a 36 and 15 year old AT patient respectively, the cytogenetic FISH analysis of ATM and TP53 was warranted. Two copies each of ATM and TP53 were detected in the control 2139 and AT cells (AT2Bi and AT3Bi) in the specific cells that were analysed and therefore no specific deletion was detected. There is well-documented evidence of the heterogeneity in AT mutation types which lead to defective ATM (60-62), and a significant proportion are attributed to missense mutations which would not be detectable at the cytogenetic level and would require molecular characterisation. However, given the established presence of both copies of ATM by FISH in all cell lines, knowledge of the mutation type was not required. However, the G-banding karyotyping analysis led to a surprising incidental finding in the control 2139 cells. The absence of an X-chromosome was evident and is characteristic of Turners syndrome. There are conflicting reports of chromosomal radiosensitivity levels in Turner syndrome cells. In one report, 5 patients with the $45, X$ karyotype compared to 9 controls irradiated with X-ray (200 rads) demonstrated chromosomal aberrations similar to the controls, indicating the $\mathrm{X}$-monosomy does not influence IR-induced chromosomal aberrations (63). However, another report demonstrated elevated levels of chromosomal radiosensitivity after 3 Gy IR in two comparative Turners syndrome variants variants ( $45 \mathrm{X}$ complement and $46 \mathrm{XX}$ gonadal dysgenesis) that were compared to age- and sex- matched controls (64). There is limited evidence in the literature to support either hypothesis. In light of this cytogenetic incidental finding, an additional control lymphoblastoid cell line (C1) was later incorporated as an additional control to 2139 where possible.

The $\mathrm{YH} 2 \mathrm{AX}$ biomarker was utilised to measure the IR-induced DNA damage response in all cell lines (C1, 2139, AT2Bi and AT3Bi). ATM phosphorylation of the variant histone H2AX on serine $139(\gamma \mathrm{H} 2 \mathrm{AX})$ localises as discrete nuclear foci quantifiable by immunoflluorescence of which 
a one to one correlation between radiation-induced DSBs and $\mathrm{\gamma H} 2 \mathrm{AX}$ foci can be recorded.

The formation of these foci has been shown to be the recognition step for the nonhomologous end joining (NHEJ) DNA repair pathway (15-17). No significant differences between the cell lines in $\mathrm{\gamma H} 2 \mathrm{AX}$ positivity was observed. A study on 40 human cell lines representing 8 different syndromes to detect a quantitative correlation of cellular radiosensitivity with various biomarkers; including $\mathrm{yH} 2 \mathrm{AX}$, reported that the IR-induced ${ } \mathrm{H} 2 \mathrm{AX}$ foci did not predict moderate radiation sensitivities (65). Similarly, $\mathrm{H}_{2} \mathrm{AX}$ foci in $\mathrm{T}$ lymphocytes derived from radiotherapy-treated gynacological cancer patients did not correlate with late radiotoxicity, however the same authors reported a linear dose reponse with gamma radiation for whole blood and isolated T-lymphocytes (66). A recent critical review of the functional assays for individual radiosensitivity determined that $\mathrm{pH} 2 \mathrm{AX}$ immunofluorescence alone was not sufficient to predict radiosensitive cases and that other cytogenetic biomarkers or cell survival bioassays are too time consuming to predict radiosensitivity in routine clinical use (67). This further necessitates the requirement for further molecular biomarkers.

Given the overall poor correlation of radiosensitivity with the cytogenetic and $\mathrm{\gamma H} 2 \mathrm{AX}$ biomarkers in our lymphoblastoid cell lines, a genetic approach was favoured but with complementarity to the previous chromosome and DNA damage biomarkers, with a focus on the ATM/chk2/P53 pathway with other DNA damage and repair mechanisms. A microRNA (miR) expression panel of $752 \mathrm{miR}$ was performed on the control (2139) and AT (AT2Bi and AT3Bi) cell lines and a panel of gene targets for the most differentially expressed miR was compiled, with an emphasis on DNA damage response genes to align with our chromosome and DNA damage biomarkers related to the $A T M / c h k 2 / P 53$ signalling pathway. One of the limitations of this study was the reliance of only one control (2139) cell line, which was due 
to the high cost associated with the microRNA experiment. Upregulated microRNAs of miR$152-3 p(43)$, miR4-24-5p (46) and miR-92-15p (48) indicated that PTEN (phosphatase and tensin homolog) was a potential target and all downregulated miR indicated both PTEN and CCDN1 genes as potential targets. The expression of both PTEN and CCCDN1 genes were analysed in all cell lines and were shown to be upregulated expressed at the lower IR dose of $0.05 \mathrm{~Gy}$. Interestingly, the $\mathrm{C} 1$ control showed no significant expression of PTEN compared to 2139, AT2Bi and AT3Bi, with a dose-dependent expression profile for CCDN1. PTEN negatively regulates the PI3-Kinase/Akt pathway and has been associated with radiosensitivity and impaired double strand break repair in lung and prostate cancer cells $(68,69)$. Other studies have reported that PTEN mutations lead to radioreistant phenotypes in glioblastoma (GBM) (68) with resistance mechanisms mediated by phosphorylation of PTEN on Tyrosine240 (pY240-PTEN,) leading to DNA repair through Rad51 (70). CCDN1 is the regulatory subunit of cyclin dependent kinases (CDK) which phosphorylates and inactivates retinoblastoma (RB) protein to promote cell cycle progression in the $\mathrm{G} 1 / \mathrm{S}$ stage, and is directly signalled through the ATM/Chk2/P53 pathway. Both potential biomarkers are related to the DNA damage and repair mechansisms induced by ionising radiation and warrant further invesitgation and validation with more radiation doses, cell lines or biological models.

\section{CONCLUSION}

There was an unexpectedly poor correlation orbserved between the control 2139 cell line with the AT (AT2Bi and AT3Bi) cell lines using cytogenetic and yH2AX biomarkers, most likely due to the underlying cytogenetic abnormality identified in the control 2139 cells. However, this is not withstanding the fact that these biomarkers have proved invaluable for other associated studies carried out at our Institute $(35-37,58)$. When a genetic approach analysing 
miR and their gene targets was taken, a better comparison could be made between the control 2139 and AT cells. This miR analysis indicated potential genetic biomarkers of radiosensitivity as well as providing mechanistic insights into the low dose radiation response particularly for $0.05 \mathrm{~Gy}$. Although the speed at which molecular work can be conducted with the provision of additional mechanistic information of radiation response, it is also important that the traditional more time-consuming methods of cytogenetics and cell survival should not be overlooked. These assays are nontheless hugely informative and reliable, and they are supported by decades of work in radiation research and in contrast, molecular technologies are advancing at a rapid rate with far less validation. When undertaking a molecular study on radiosensitivity biomarkers, we suggest a multi-biomarker approach to include optimised traditional methods with considerations for the biological model, dose-dependance and the scale of the study.

The authors acknowledge funding from the European Union Network of Excellence on Low Dose Research towards Multidisciplinary Integration (DoReMi) (2010-2016), grant number 249689 and from Science Foundation Ireland (grant number 11/RFP.1/BMT/3317).

\section{ACKNOWLEDGEMENTS}

(1)


this assay be used for rapid biodosimetry in a large scale radiation accident?. Mutation Research. 2013;756 (1-2): 170-173.

2. Romm, H.,Ainsbury, E.,Barnard, S.,Barrios, L.,Barquinero, J. F.,Beinke, C., Deperas, M.,Gregoire, E.,Koivistoinen, A.,Lindholm, C.,Moquet, J.,Oestreicher, U.,Puig, R., Rothkamm, K.,Sommer, S.,Thierens, H.,Vandersickel, V.,Vral, A.,Wojcik, Andrzej. Validation of semi-automatic scoring of dicentric chromosomes after simulation of

3. Dimphy Zeegers, ${ }^{1}$ Shriram Venkatesan, ${ }^{1}$ Shu Wen Koh, ${ }^{1}$ Grace Kah Mun three different irradiation scenarios. Health Physics. 2014: 106 (6): 764-771 Low, ${ }^{1}$ Pallavee Srivastava, ${ }^{1}$ Neisha Sundaram, ${ }^{1}$ Swaminathan Sethu, ${ }^{1,2}$ Birendranath Banerjee,,$^{1,3}$ Manikandan Jayapal, ${ }^{1,4}$ Oleg Belyakov, ${ }^{5}$ Rajamanickam Baskar, ${ }^{6}$ Adayabalam S. Balajee, ${ }^{7}$ and M. Prakash Hande. Biomarkers of Ionizing Radiation Exposure: A Multiparametric Approach. Genome Integr. 2017; 8: 6. doi: $10.4103 / 2041-9414.198911$

4. Pernot $E^{1}$, Hall J, Baatout $S$, Benotmane MA, Blanchardon $E$, Bouffler $S$, et al. Ionizing radiation biomarkers for potential use in epidemiological studies. Mutat Res. 2012; 751(2):258-86.

5. http://www.melodi-online.eu/doremi.html

6. Hall J, Jeggo PA, West C, Gomolka M, Quintens R, Badie C, et al. Ionizing radiation biomarkers in epidemiological studies - An update. Mutat Res. 2017; 771:59-84.

7. Gráinne O’Brien, Lourdes Cruz-Garcia, Matthäus Majewski, Jakub Grepl, Michael Abend, Matthias Port, Aleš Tichý, Igor Sirak, Andrea Malkova, Ellen Donovan, Lone Gothard, Sue Boyle, Navita Somaiah, Elizabeth Ainsbury, Lucyna Ponge, Krzysztof Slosarek, Leszek Miszczyk, Piotr Widlak, Edward Green, Neel Patel, Mahesh Kudari, Fergus Gleeson, Volodymyr Vinnikov, Viktor Starenkiy, Sergii Artiukh, Leonid Vasyliev, Azfar Zaman \& Christophe Badie. FDXR is a biomarker of radiation exposure in vivo. Scientific Reports. 2018, 8 (684). DOI:10.1038/s41598-017-19043

8. Abend M, Badie C, Quintens R, Kriehuber R, Manning G, Macaeva E, et al. Examining Radiation-Induced In Vivo and In Vitro Gene Expression Changes of the Peripheral 
Blood in Different Laboratories for Biodosimetry Purposes: First RENEB Gene Expression Study. Radiat Res. 2016; 185(2):109-23.

9. Macaeva E, Saeys Y, Tabury K, Janssen A, Michaux A, Benotmane MA, et al. Radiationinduced alternative transcription and splicing events and their applicability to practical biodosimetry. Sci Rep. 2016; 6:19251.

10. Manning G, Kabacik S, Finnon P, Bouffler S, Badie C. High and low dose responses of transcriptional biomarkers in ex vivo X-irradiated human blood. Int J Radiat Biol. 2013; 89(7):512-22.

11. Manning G, Macaeva E, Majewski M, Kriehuber R, Brzóska $K$, Abend $M$, et al. Comparable dose estimates of blinded whole blood samples are obtained independently of culture conditions and analytical approaches. Second RENEB gene expression study. Int J Radiat Biol. 2017; 93(1):87-98.

12. Badie C, Kabacik S, Balagurunathan Y, Bernard N, Brengues $M$, Faggioni G, et al. Laboratory intercomparison of gene expression assays. Radiat Res. 2013; 180(2):13848.

13. Maréchal A, Zou L. DNA damage sensing by the ATM and ATR kinases. Cold Spring Harb Perspect Biol. 2013;5 (9).

14. Graham ME, Lavin MF, Kozlov SV. Identification of ATM Protein Kinase Phosphorylation Sites by Mass Spectrometry. Methods Mol Biol. 2017; 1599:127-144.

15. Valdiglesias V, Giunta S, Fenech M, Neri M, Bonassi S. $\mathrm{yH} 2 \mathrm{AX}$ as a marker of DNA double strand breaks and genomic instability in human population studies. Mutat Res. 2013; 753(1):24-40. 
16. Willers $H$, Gheorghiu L, Liu Q, Efstathiou JA, Wirth LJ, Krause $M$, et al. DNA Damage Response Assessments in Human Tumour Samples Provide Functional Biomarkers of Radiosensitivity. Semin Radiat Oncol. 2015; 25(4):237-50.

17. De-Colle C, Yaromina A, Hennenlotter J, Thames $H$, Mueller AC, Neumann $T$, et al. Ex vivo $\mathrm{yH} 2 \mathrm{AX}$ radiation sensitivity assay in prostate cancer: Inter-patient and intrapatient heterogeneity. Radiother Oncol. 2017; 124(3):386-394.

18. Rothkamm K, Bernard S, Moquet J, Ellender M, Rana Z, Burdak-Rothkamm S. DNA damage Foci: Meaning and Significance. Environmental and Molecular Mutagenesis. 2015. 56: 491-504

19. Taylor AM, Groom A, Byrd PJ. Ataxia-telangiectasia-like disorder (ATLD)-its clinical presentation and molecular basis. DNA Repair (Amst). 2004; 3(8-9):1219-25.

20. Taylor AM, Lam Z, Last JI, Byrd PJ. Ataxia telangiectasia: more variation at clinical and cellular levels. Clin Genet. 2015; 87(3):199-208.

21. Lavin MF, Kozlov S, Gatei M, Kijas AW. ATM-Dependent Phosphorylation of All Three Members of the MRN Complex: From Sensor to Adaptor. Biomolecules. 2015

22. Hafner A, Bulyk ML, Jambhekar A, Lahav G. The multiple mechanisms that regulate p53 activity and cell fate. Nat Rev Mol Cell Biol. 2019; 20(4):199-210.

23. Toulany M. Targeting DNA Double-Strand Break Repair Pathways to Improve Radiotherapy Response. Genes (Basel). 2019; 10(1).

24. Macaulay VM, Salisbury AJ, Bohula EA, Playford MP, Smorodinsky NI, Shiloh Y. Downregulation of the type 1 insulin-like growth factor receptor in mouse melanoma cells is associated with enhanced radiosensitivity and impaired activation of Atm kinase. Oncogene 2001; 20(30):4029-40. 
25. Kemp MG, Spandau DF, Simman R, Travers JB. Insulin-like Growth Factor 1 Receptor Signaling Is Required for Optimal ATR-CHK1 Kinase Signaling in Ultraviolet B (UVB)irradiated Human Keratinocytes. J Biol Chem 2017; 292(4):1231-1239.

26. Bartłomiej Tomasik, Wojciech Fendler, and Dipanjan Chowdhury. Serum microRNAs - potent biomarkers for radiation biodosimetry. Oncotarget. 2018; 9(18):1403814039.

27. Tomasik B, Chałubińska-Fendler J, Chowdhury D, Fendler W. Potential of serum microRNAs as biomarkers of radiation injury and tools for individualization of radiotherapy. Transl Res 2018; 201:71-83.

28. Kabacik S, Manning G, Raffy C, Bouffler S, Badie C. Time, dose and ataxia telangiectasia mutated (ATM) status dependency of coding and noncoding RNA expression after ionizing radiation exposure. Radiat Res 2015;183(3):325-37.

29. Averbeck D, Salomaa S, Bouffler S, Ottolenghi A, Smyth V, Sabatier L. Progress in low dose health risk research: Novel effects and new concepts in low dose radiobiology. Mutat Res 2018; 776:46-69.

30. Gatti R.A and Painter R.B. Ataxia-Telangectasia. Nato ASI Subseries H. Book 77. Spriner Science and Media, June 29, 2013.

31. Lillicrap SC, Owen B, Williams JR, Williams PC. Code of practice for high-energy photon therapy dosimetry based on the NPL absorbed dose calibration service. Phys Med Biol 1990; 35:1355-1360.

32. Lewis D, Micke A, Yu X, Chan MF. 2012. An efficient protocol for radio-chromic film dosimetry combining calibration and measurement in a single scan. Med Phys 2012; 39:6339-6350. 
33. Fiandra C, Ricardi U, Ragona R, Anglesio S, Romana Giglioli F, Calamia E, et al. Clinical use of EBT model gafchromic film in radiotherapy. Med Phys 2006; 33:4314-4319.

34. Micke A, Lewis DF, Yu X. 2011. Multichannel film dosimetry with nonuniformity correction. Med Phys. 38:2523-2534.

35. Meade AD, Maguire A, Bryant J, Cullen D, Medipally D, White L, B, et al. Prediction of DNA damage and G2 chromosomal radio-sensitivity ex vivo in peripheral blood mononuclear cells with label-free Raman micro-spectroscopy. Int J Radiat Biol. 2019; 95(1):44-53.

36. Howe O, O'Sullivan J, Nolan B, Vaughan J, Gorman S, Clarke C, et al. Do radiationinduced bystander effects correlate to the intrinsic radiosensitivity of individuals and have clinical significance? Radiat Res. 2009; 171(5):521-9.

37. Howe O, O'Malley K, Lavin M, Gardner RA, Seymour C, Lyng F, et al. Cell death mechanisms associated with $\mathrm{G} 2$ radiosensitivity in patients with prostate cancer and benign prostatic hyperplasia. Radiat Res. 2005; 164(5):627-34

38. Taylor AM, Metcalfe JA, Thick J, Mak YF. Leukemia and lymphoma in ataxia telangiectasia. Blood. 1996; 87(2):423-38.

39. Boultwood J. Ataxia telangiectasia gene mutations in leukaemia and lymphoma J Clin Pathol. 2001; 54(7):512-516.

40. H Döhner H, S Stilgenbauer, K Döhner, M Bentz, P Lichter. Chromosome aberrations in B-cell chronic lymphocytic leukemia: reassessment based on molecular cytogenetic analysis. J Mol Med 1999; 77(2):266-81.

41. Furlong $\mathrm{H}$, Mothersill C, Lyng F, Howe O. Apoptosis is signalled early by low doses of ionizing radiation in a radiation-induced bystander effect. Mutat Res. 2013 JanFeb;741-742:35-43. 
42. Ren J.W, Li J.Z, Tu C, MiR-135 post-transcriptionally regulates FOXO1 expression and promotes cell proliferation in human malignant melanoma cells, Int J Clin Exp Pathol $2015 ; 6356-6366$.

43. Huang S, Li X, Zhu H. MicroRNA-152 Targets Phosphatase and Tensin Homolog to Inhibit Apoptosis and Promote Cell Migration of Nasopharyngeal Carcinoma Cells, Med Sci Monit 2016; 22: 4330-4337.

44. Wu L, Li H, Jia C.Y, Cheng W, Yu M, Peng $M$, et al. MicroRNA-223 regulates FOXO1 expression and cell proliferation, FEBS Lett 2012; 586: 1038-1043.

45. Wang $\mathrm{X}$, Xia $\mathrm{Y}$, microRNA-328 inhibits cervical cancer cell proliferation and tumorigenesis by targeting TCF7L2, Biochem Biophys Res Commun 2016; 475:169175.

46. Lu C, Wang H, Chen S, Yang R, Li H, Zhang G. Baicalein inhibits cell growth and increases cisplatin sensitivity of $\mathrm{A} 549$ and $\mathrm{H} 460$ cells via miR-424-3p and targeting PTEN/PI3K/Akt pathway, J Cell Mol Med 2018; 22:2478-2487.

47. Yi L, Yuan Y, MicroRNA-618 modulates cell growth via targeting PI3K/Akt pathway in human thyroid carcinomas, Indian J Cancer 2015; 52(3) E186-189.

48. Ragusa M, Statello L, Maugeri M, Majorana A, Barbagallo D, Salito L, et al. Specific alterations of the microRNA transcriptome and global network structure in colorectal cancer after treatment with MAPK/ERK inhibitors, J Mol Med 2012; 9:1421-1438.

49. Zhang J, Jin H, Liu H, Lv S, Wang B, Wang R, et al. MiRNA-99a directly regulates AGO2 through translational repression in hepatocellular carcinoma, Oncogenesis 2014; 3 : e97. 
50. Wang B, Wang D, Yan T, Yuan H. MiR-138-5p promotes TNF- $\alpha$-induced apoptosis in human intervertebral disc degeneration by targeting SIRT1 through PTEN/PI3K/Akt signaling, Exp Cell Res 2016; 345:199-205.

51. Liu X, Lv X.B, Wang X.P, Sang Y, Xu S, Hu K, M. MiR-138 suppressed nasopharyngeal carcinoma growth and tumorigenesis by targeting the CCND1 oncogene, Cell Cycle 2012; 11:2495-2506.

52. Jin Y.Y, Chen Q.J, Xu K, Ren H,T, Bao X, Ma Y.N, et al. Involvement of microRNA-141$3 p$ in 5-fluorouracil and oxaliplatin chemo-resistance in esophageal cancer cells via regulation of PTEN, Mol Cell Biochem 2016; 422: 161-170.

53. Li J.Z, Li J, Wang H.Q, Li X, Wen B, Wang Y.J. MiR-141-3p promotes prostate cancer cell proliferation through inhibiting kruppel-like factor-9 expression, Biochem Biophys Res Commun 2017; 482: 1381-1386.

54. Shen L.M, Song Z.W, Hua Y, Chao X, Liu J.B. miR-181d-5p promotes neurite outgrowth in PC12 Cells via PI3K/Akt pathway, CNS Neurosci Ther 2017; 23: 894-906.

55. Vickers M.M, Bar J, Gorn-Hondermann I, Yarom N, Daneshmand M, Hanson J.E, et al. Stage-dependent differential expression of microRNAs in colorectal cancer: potential role as markers of metastatic disease, Clin Exp Metastasis 2012; 29:123-132.

56. Li D, Zhao Y, Liu C, Chen X, Qi Y, Jiang Y, et al. Analysis of MiR-195 and MiR-497 expression, regulation and role in breast cancer, Clin Cancer Res 2011; 17: 1722-1730.

57. Maguire A, Vega-Carrascal I, Bryant J, White L, Howe O, Lyng F.M, et al. Competitive evaluation of data mining algorithms for use in classification of leukocyte subtypes with Raman microspectroscopy. Analyst 2015; 140: 2473-2481 
58. Maguire A, Vegacarrascal I, White L, McClean B, Howe O, Lyng F.M, et al. Analyses of ionizing radiation effects in - vitro in peripheral blood 1 lymphocytes with Raman spectroscopy. Radiation Research 2015; 183(4) 407-416.

59. Rothkamm K, Barnard S, Moquet J, Ellender M, Rana Z, Burdak-Rothkamm S. DNA damage foci: Meaning and significance. Environ Mol Mutagen. 2015 Jul;56(6):491504. doi: 10.1002/em.21944.

60. Vorechovsky I, Luo L, Prudente S, Chessa L, Russo G, Kanarious M, et al. Exon-scanning mutation analysis of the ATM gene in patients with ataxia-telangiectasia. Eur J Hum Genet 1996; 4:352-5.

61. Baumer A, Bernthaler U, Wolz W, Hoehn H, Schindler D. New mutations in the ataxia telangiectasia gene. Hum Genet 1996; 98:246-9.

62. Davis MY, Keene CD, Swanson PD, Sheehy C, Bird TD. Novel mutations in ataxia telangiectasia and AOA2 associated with prolonged survival. J Neurol Sci 2013; $335: 134-8$.

63. Kuznetsova M.V, Trofimov D.Y , Shubina E.S , Kochetkova T.O , Karetnikova N.A, Barkov I.Y, et al. Two Novel Mutations Associated With Ataxia-Telangiectasia Identified Using an Ion AmpliSeq Inherited Disease Panel. Front. Neurol 2017; 570 (8): $1-8$

64. Garcia Heras J, Coco R. Chromosomal sensitivity to X-rays in lymphocytes from patients with Turner syndrome. Mutat Research 1986; 160(1):33-38

65. Joubert A, Zimmerman K.M, Bencokova Z, Gastaldo J, Chavaudra N, Favaudon V, et al. DNA double-strand break repair defects in syndromes associated with acute radiation response: at least two different assays to predict intrinsic radiosensitivity? Int J Radiat Biol 2008; 84(2):107-25. 
66. Werbrouck J, De Ruyck K, Beels L, Vral A, Van Eijkeren M, De Neve W, et al. Prediction of late normal tissue complications in RT treated gynaecological cancer patients: potential of the gamma- $\mathrm{H} 2 \mathrm{AX}$ foci assay and association with chromosomal radiosensitivity. Oncol Rep 2010; 23(2):571-8.

67. Ferlazzo M.L, Bourguignon M, Foray N. Functional Assays for Individual Radiosensitivity: A Critical Review. Semin Radiat Oncol 2017; 27(4):310-315.

68. Pappas G, Zumstein L.A, Munshi A, Hobbs M, Meyn R.E. Adenoviral-mediated PTEN expression radiosensitizes non-small cell lung cancer cells by suppressing DNA repair capacity. Cancer Gene Ther 2007; 14(6):543-9.

69. Rosser C.J, Tanaka M, Pisters L.L, Tanaka N, Levy L.B, Hoover D.C, et al. Adenoviralmediated PTEN transgene expression sensitizes Bcl-2-expressing prostate cancer cells to radiation. Cancer Gene Ther 2004; 11(4):273-9.

70. McEllin B, Camacho C.V, Mukherjee B, Hahm B, Tomimatsu N, Bachoo R.M, et al. PTEN loss compromises homologous recombination repair in astrocytes: implications for GBM therapy with temozolomide or PARP inhibitors. Cancer Res 2010; 70(13):545764. 